Review of:

\section{The Foundations of Bioethics}

\author{
Paola Cavalieri \\ Milan, Italy
}

\section{The Foundations of Bioethics by Hugo}

Tristram Engelhardt Jr. (Oxford

University Press, New York, 1986)

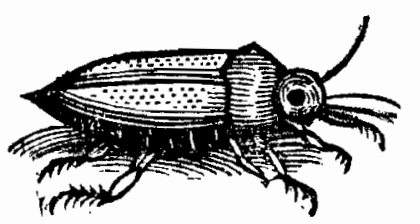

Since its start, bioethics played an important role in bringing about change. This happened at two levels: at the level of theory, through the challenge that many of the inost respected scholars in the field made to the conventional doctrine of the sanctity of human life; and at the level of practice, through the opportunity it offers to confront problems in a rational, pluralistic way, comparing different arguments and different substantive positions.

At the first level, the discussions about abortion and euthanasia, leading to the distinction between being human in a descriptive, biological sense and being human in an evaluative, philosophical sense (that is, being rational, autonomous etc.), launched an attack on the view that has been termed as "humanism." As it has been emphasized, humanism has, so to speak, two sides: an inclusive one which holds that all humans have equal moral status, and an exclusive one which holds that only humans have equal moral status. ${ }^{1}$ The critique which has been put forward as to the inclusive side led to a critique of the exclusive side, thus furthering the revision of the traditional notion of moral community which animal liberation ethics pursues. While the evidence of this overlapping is wide, it could be enough

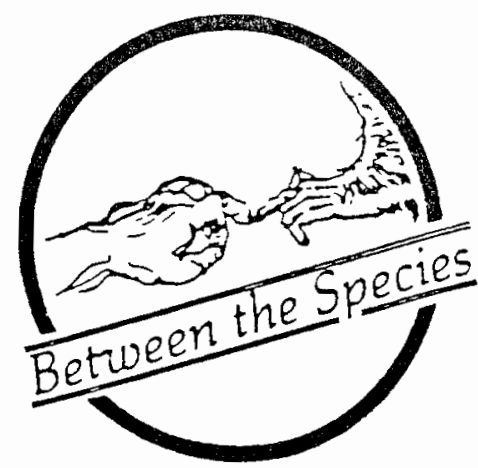

here to mention the challenge to the moral relevance of species Michael Tooley presents in his seminal essay on abortion and infanticide and James Rachels' acknowledgment of the role played by the abandonment of speciesist prejudice in the development of his views about euthanasia. ${ }^{2} \mathrm{~A}$ serious rethinking of the moral status of nonhumans seems thus to be a major element in bioethical reflection.

The second, practical kind of impact bioethics can have has been the object of some reflection in the relevant literature. It was even said that medicine saved the life of ethics as a social practice, after the long period of mainly theoretical inquiries covering at least the first sixty years of the twentieth century. ${ }^{3}$ Without going to such extremes, however, some interesting explorations of the possible role of bioethical discussions have been offered. In a recent article, for example, Peter Singer, starting from the real case of an infant with Down's syndrome, sketches a sort of ideal bioethical debate which shows how, even if we grant that the basis of ethical judgments is immune from rational criticism, ample scope is left for the application of reason and argument, and accordingly for bioethics to play an important role in the application of ethics in a largely secular society. ${ }^{4}$

Both these radical features of bioethics-the critique of humanism and the innovative social function--can be found in The Foundations of Bioethics by Tristram
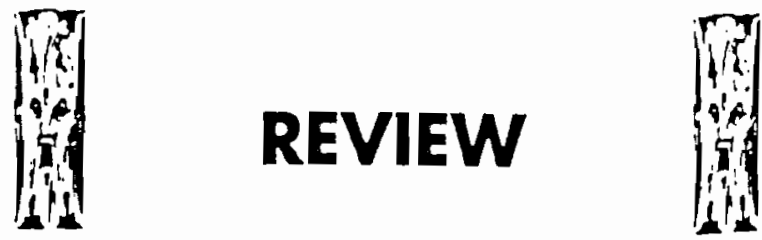
Engelhardt Jr. They have, however, undergone a curious process. While the latter has swollen out of proportion, to the extent that it has becoine the core of the volune, the former has notably shrunk, due to the disappearance of one of its horns, the critique of the exclusive side of humanism. It is this particular aspect of Engelhardt's argument, which enables him to lightheartedly license not only the employment of millions of nonhumans in medical practices, but also their use for food and even sport, the one I want to focus on. To do this, however, I shall have to deal with the other. Not only, in fact, are they inextricably interwoven, but it is precisely starting from his conception of the bioethical arena that Engelhardt develops his view of the moral status of nonpersons, both human and nonhuman. One notion is central to this context, as well as to the whole book: the notion of peaceable community.

\section{The peaceable community I: historical}

Before starting, it will be useful to give an idea, however approximate, of the structure of The Foundations of Bioethics. After putting bioethics in its historical context and discussing at some length the nature of ethics, the author gets on to his specific subject with the enunciation and justification of the two principles he sees as the basis of bioethics: the principle of autonomy and the principle of beneficence. Such a basis is further explained and illustrated in the section on persons, possessions and state authority and-after an illuminating digression on the different possible approaches to disease (evaluative, descriptive, explanatory etc.) - its implications are explored with regard to problems like abortion, infanticide, free and informed consent, suicide and euthanasia. Finally, the issue of the "rights to health care" leads the author to make a rapid incursion into the field of political philosophy, tackling problems such as justice and inequality. Where does the peaceable community fits into this picture? The notion appears at every crucial step in the argument: but, I shall argue, with different meanings.

"In this volume I will talk of peaceable secular pluralistic societies so as to indicate societies including a diversity of moral viewpoints, and enjoying in addition a freedom of moral opinion without the fear of repression."(4) This can be considered the first appearance of the peaceable community. Both its formulation and its context characterize it in a precise way: the idea of the peaceable conmunity is concrete and historical. It has to be realized here: in a Western society which embraces "not only America and Europe, but societies such as Japan and Taiwan as well,"(6) and one can imagine that the author, if writing now, would include the ex-Soviet Union too. And it has to be pursued now: in a moment when historical forces "have led to the major institutions of most democracies no longer being associated in a significant fashion with an established church."(4) Having included among the religions of the world also overall worldviews like Marxism, Engelhardt goes on to say that a peaceable secular society is characterized by the absence of any particular religious or moral orthodoxy imposed by force.

If taken as an actual description of the specific society he refers to, I do not think this statement matches reality. It is true that in Western society many areas of moral life which were once dominated by dogmatic views are now open to different approaches; but it seems equally true that the countries in which we live accept some basic principles in whose defence the resort to force is accepted - e.g. that taking the life and infringing the liberty of (at least) adult humans is prima facie wrong, while nonhuman lives are expendable. And it won't do to say that, as the author will argue later, these are (some) of the few principles a peaceable community can, indeed should, accept: in this context, this would simply beg the question. The historical version of the peaceable community can make sense only in the restricted ineaning of a sub-community, whose peaceable debates should confine themselves to the particular spheres of social life that are not covered by the forced imposition of the society's (basic) moral orthodoxy. This is not, however, the author's own interpretation, since his goal is more ambitious.

\section{The peaceable community II: ethical}

I shall now try to follow the line of reasoning that attempts to achieve such a greater goal. This is no easy task, as the argument is dispersed and seems to appear and vanish, as a subterranean stream, in different moments and contexts. The starting point is the alleged impossibility of justifying a particular moral viewpoint. In the author's opinion, after the historical failure of the religious attempt to impose a unitary morality and the collapse of the Humanistic hope to provide a secular, general justification of a specific moral viewpoint, we are forced to accept what he metaphorically calls the 
"polytheistic presumption"- that is, the idea that there are a number of equally defensible, but quite different, moral perspectives. Engelhardt supports his point through a rapid survey of the major secular attempts to reach objectivity in ethics, attempts that he rejects in turn, mainly on the charge of being question begging. One could quibble with the details of his account, such as the overlooking of the fact that preference utilitarianism is a form of consequentialism which does not "need already to know which consequences are better or worse than others,"(31) or the partially misleading reference to Henry Sidgwick on the subject of intuitionism.(33) One could also question the way he gathers in a single list of allegedly inadequate "standards in ethics" such different items as characterizations of the ethical such as the reference to the idea of inpartiality, questions in ethics such as the appeal to the consequences of actions or to natural law, and theories about ethics such as the claim that moral principles can be grasped by intuition. Engelhardt's conclusion is, at any rate, that all concrete moral choices fail as they already presuppose a particular moral sense, and that such a result could bring us to nihilism, but for a saving factor: the possibility of creating commonly accepted procedures. For this to succeed generally, however, an inescapable procedural basis is needed: "This basis, if it is to be found at all, will need to be disclosable in the very nature of ethics itself. Such a basis appears to be available in the minimum notion of ethics as an alternative to force in resolving moral controversies."(41) From the alleged individuation of a transcendental condition-in the sense of existence condition-for the moral world stems a central role for consent: the conclusions to the process of ethical reasoning are those that peaceable negotiators have all agreed to accept. To be a negotiator, one should be selfconscious, rational and in possession of a sense of moral concern, i.e. one should be a moral agent, or a person; and the community of negotiators is the moral community, ${ }^{5}$ or the "inner sanctum of morality" where the transcendental condition for ethics finds expression in the principle of autonomy, or mutual respect. ${ }^{6}$

The picture is starting to take shape. Engelhardt's claim is twofold: he argues that his conclusion is inescapable and purely formal. I shall object to both contentions in turn. While the criticism of the latter requires that we pursue the argument a little further, the former can already be dealt with. Though the author himself wouldn't agree with this description-and in fact he carefully avoids using the term-what the attempt to avoid nihilism has produced is something akin to a version of contractarianism, i.e. of the view that the demands of morality are fixed by agreement. Does the argument's premise actually entail this conclusion? And, in the first place, what exactly is the premise? Engelhardt's starting point is the alleged impossibility of justifying a particular moral viewpoint. Such "polytheistic presumption" seems to imply relativism--i.e. the doctrine according to which no single moral code has universal validity. If it actually does is, however, difficult to detect. The author's account of the failure of the attempts to assert a particular moral viewpoint is both theoretical and factual. It is theoretical when the various methods and theories in ethics are considered and criticised; and it is factual when the "crumbling of the presumed possibility of a uniformity of moral viewpoint" is linked up with Luther's ninety-five thesis, (3) or when we are told that, whenever we consider a society of fair scope, we will have a pluralism of moral beliefs. The latter approach does not entail meta-ethical relativism, as is proved, to make just one example, by the position of Alasdair MacIntyre, whose historical account Engelhardt mentions in support of his own analysis. $(9)^{7}$ If relativism is not entailed, it remains possible to hold a universalist position, that is, to conceive of a particular normative theory having objective validity; accordingly, not only the discovery of a specific procedural basis for ethics, but also the general search for it is not "inescapable." If, on the other hand, the statement of the impossibility of asserting a universally valid moral viewpoint is theoretical, what we face is meta-ethical relativism; but then, "inescapability" is precluded by the very same doctrine. It is precluded, at least, unless one makes some assumptions, which transform the pure version of relativism into a more qualified one. And this is exactly what Engelhardı does-and admits of doing. In the same passage in which he acknowledges his debt towards MacIntyre, he comments: "I, unlike Macintyre, hold that there is a vindication for a shred of the Enlightenment dream: the rationality of resolving moral controversies through agreement." (63, n. 48) To assume the value of agreement (and peace) is to make a choice: and it is from this choice, and not from relativism, that the necessity of a procedural basis stems. Engelhardt himself seems aware of this problem. A few pages after charging Rawls with circularity, on the grounds that each specific description of the original position-that 
is, of the hypothetical contracting situation-already presupposes a theory of justice, and thus cannot produce one, he tries to face the same difficulty with regard to his own theory. He writes: "As such, this analysis has the character of unpacking a tautology. Such circular reasoning (i.e., reasoning from the notion of ethics as the enterprise of resolving moral controversies without a fundamental recourse to force, to the principle of respecting the freedom of participants in a controversy as the basis of ethics) is tolerable if it discloses the character of a major element of the lives of persons."(46) I don't think the attempted defence can work. The notion of person is in this context an extraneous, unwarranted element which, far from providing justification, is in need of justification. Without it, Engelhardt's selfcritical remark on circularity stands, clearly undermining any claim to inescapability.

If the argument is not inescapable, is it at least purely formal? The adjective Engelhardt uses to qualify it, "transcendental," is overtly borrowed from Kant; and other features of the theory, in the first place the role ascribed to respect for persons and the attribution of a particular moral status to moral agents, are remindful of Kantian ethics. Engelhardt is, however, critical of his great model; and a discussion of his claims will cast light on the problems with his theory. The criticism is rather original, given the frequency of the opposite accusation of formalism: Kant is charged with "smuggling concreteness" into what should be a purely procedural framework. Though Engelhardt focuses on two elements, the condemnation of suicide and the obligation of beneficence, I shall not consider his objections to the former, which has not been taken too seriously beginning at least from Schopenhauer; ${ }^{8}$ the critique of the latter is, on the contrary, of great importance, as it leads to a detaching from Kant's account of the moral domain. In brief, Engelhardt claims that Kant's reliance on a contradiction of the will rather than on a conceptual contradiction in order to ground a principle of beneficence shows how beneficence cannot be generated by a purely formal thesis. Feeling thus confirmed in his view that, while the principle of autonomy is connected with procedure, the principle of beneficence is linked with content, he contrasts the equation form/universality to the equation content/ particularity, and confines to the realm of subjectivity a beneficent commitment which is perceived as a collection of "concrete accounts of virtues and vices" and of "different understandings of the good life." Given its non-procedural character, the principle of beneficence is weaker than, and subordinate to, the principle of autonomy; but for this very reason it is not confined to the realm of moral agents. With a further variation on his dichotomic structure, which matches the deontological character of respect for autonomy with the teleological_-"and most likely utilitarian"- character of the obligation of beneficence, Engelhardt grounds the attempt to secure the maximal balance of benefits over harms not only for persons, but also for the entities that inhabit the no-man's-land outside the moral community.

This marks the collapse of what has been called the agent/patient parity principle ${ }^{9}$ - the principle that moral patients must be moral agents-and creates a category of second-class moral patients. Generically labeled as animal life, those beings include nonhuman animals and various human nonpersons, such as zygotes, embryos, fetuses, infants, the senile and the severely disabled. The sort and intensity of the duties towards those beings will vary in relation to a hierarchy based on their level of consciousness, but not only. In fact, the principle of beneficence is doubly constrained: first, it works within the bounds of respecting autonomy; second, it changes according to the different understandings of different moral agents. Furthermore, given that persons have a right of preemption on welfare which discounts the claims of nonpersons, it can happen that beings at the bottom of the hierarchy are thrown to its top, and even granted the status of persons "in the social sense," only on the grounds of the utility this yields for actual persons.

Such a changing account of the moral domain at first sight lays itself open to an internal criticism. The binary, hierarchical-and somewhat mechanicalview of the moral life Engelhardt embraces collides with the main tenet of his theory, i.e. the principle of respecting the freedom of participants in a moral controversy. Engelhardt seems to forget that there are ethical views in which the duty of beneficence, far from grounding only a secondary commitment, lies at the core of the moral life. Utilitarianism is an example; and one of the features of utilitarian theory is that its constituency includes all sentient beings. Engelhardt's view would require that utilitarians, faced with a situation in which they could maximize positive consequences by relieving the suffering inflicted by a person to nonpersons-say, animals-refrain from 
doing this in the name of the principle of autonomy. This would simply amount to asking them to give up what they see as their overriding duty, and accordingly to be immoral on their own view. How can this fit with respecting the freedom of the participants in moral controversies?

But the real problem, the one that invalidates the claim to formalism and discloses the substantive nature of the theory, is elsewhere. It lies in the subdivision of the moral domain into two levels. In Kant's theory, thanks to the agent/patient parity principle, the principle of autonomy covers the whole constituency. Kant's argument can be purely formal because the version of the categorical imperative that is known as the "formula of the end in itself," which demands that we treat "humanity, both in [our] own person and in the person of every other, always as an end, never as a means merely," 10 acts as a side constraint with reference to all the parties in the moral domain. One can object to Kant's withholding of any moral considerability from nonrational beings, or to the equation he establishes between rational beings and humans, ${ }^{11}$ but, once such an account is accepted, respect for persons is really a purely formal requirement. If, on the other hand, we break the unity of the moral domain, as it is the case with the doctrine of the two levels, every formal principle which is confined to one of them, and does not involve just a distinctive sort of moral constraint, but a special weighty one, ${ }^{12}$ becomes substantive with respect to the other. This is exactly what happens with Engelhardt's stratified moral domain. Since the principle of autonomy and the principle of beneficence are arranged in lexical order - that is, the first one has to be fully satisfied before it becomes possible to move on to the second-and since the parties in the lower level are not covered by the principle of autonomy, the claims of the second-class moral patients will always be overridden by the claims of the members of the moral community. To put it in other terms, beingowed-respect will directly result in cashing out special moral status.

Thus, to say that only persons are owed respect is not simply to provide existence conditions for the ethical: it is also to advance a substantive interpretation of ethics. The charge of "smuggling concreteness" into what should have been a merely procedural argument that was directed against Kant seems more suited to the one who made it.

\section{The peaceable community III: political}

Contract theories are most often social contract theories, and the present one constitutes no exception. Engelhardt clearly states that secular ethics is an enterprise in public policy making, and behind the question "how can we establish the moral world?" always lurks the question "how can we establish a peaceable secular pluralist society?" 'Though the book devotes much room to the discussion of the social and economic features of such a society, what is relevant here is the underlying structure, which closely follows the structure of the moral domain. The basic dichotomy is once again easily detectable: on the universal, objective side, there is the state, a political association whose members do not necessarily share a common, concrete view of the good; on the particular, subjective side, there are the different communities which live on shared, specific moral perspectives. The procedural focus of the state expresses itself in securing the mutual respect of persons, i.e. offering the impartial protection of citizens from murder, robbery, and other unauthorized touchings of themselves or their property--a property which, on Engelhardt's view, includes many second-class moral patients, i.e. nonhuman animals, young children and "mere human biological organisms."(134) While moral authority comes from the consent of peaceable moral agents, basic political authority comes from the implicit consent of peaceable citizens, interested in being safeguarded from unconsented-to force ${ }^{13}$ On the other hand, the lives of those same citizens will take on full significance only in particular moral worlds--say, the communities of Orthodox Jews, Texian deists or Black Moslems-w which give instruction regarding peculiar moral values to pursue.

Being a sort of projection of the ethical construction, Engelhardt's political theory shares most of its difficulties. The different character of the political context, however, alters their impact. In particular, since in social and political life, as contrasted to the ethical sphere, we are prepared to give up some of our demands in favour of the results of "a decision procedure which represent[s] a fair compromise between competing claims to power," 14 the idea of the priority of generally agreed-on rules over more local claims becomesalthough with some important provisos-plausible. The political framework can also cast some light on the peculiar fact that, though no clear differentiation between "ethical" and "moral" is proposed, Engelhardt 
defines ethics as the enterprise of resolving moral controversies: if correlated with the existence of the particular moral worlds described above, such definition acquires a precise meaning.

This very meaning, however, points out further problems. The focus on moral controversies is made possible by the fact that fundamental nonmoral problems are tackled by the state through basic protection from murder, robbery, and other unauthorized touchings. But which beings are so protected? Only persons-the second-class moral patients being debarred from the side constraints which apply in the moral community, and accordingly from the protective scope of the law. As the role of warrantor of respect for persons played by political authority is expressed in protecting innocent persons ${ }^{15}$ from assault as well as from interference, not only nonhuman animals, but also human nonpersons are left at the mercy of the particular moral worlds-though Engelhardt manages to avoid the most unpopular outcomes of his theory through the notion of social person. The application of this doctrine, usually confined to nonhuman animals, to members of our species has the effect of emphasizing a fundamental problem, which occurs both in the political domain and in the moral one. In neither sphere are persons_even supposing that they are the only moral or political agents--the only agents, ${ }^{16}$ and it is difficult to see why (qualified) noumoral freedom from interference should be a priori accorded only contingently on (qualified) moral freedom from interference. Engelhardt's explanation seems to be that persons being the source of moral values, they are the existence condition for the peaceable community. However, this does not mean that they are the only members of such community, or the only beings which have ultimate value (and which should accordingly be unconditionally protected). To say this would amount to confusing how the values of an ethic are to be achieved with what is to be achieved by such an ethic. ${ }^{17}$ Engelhardt appears to mingle, once again, formal and substantive. Though the moral capacity, and accordingly the entities which possess it, play an essential role in a purely formal thesis about values, the thesis that only moral agents have ultimate moral standing is not a purely formal thesis about values. Rather than supplying existence conditions for all claims about values, it advances one such claim. It is therefore a substantive thesis about the beings that have ultimate value or moral standing. ${ }^{18}$ If, consequently, selective protection for persons is not warranted by the argument from moral agency, different reasons must be offered for Engelhardt's radically dichotonic political doctrine to stand.

\section{Conclusion}

I have argued that the structure of the peaceable community, be it historical, ethical or political, is deeply flawed. If my arguments are sound, Engelhardt's foundations cannot sustain the overgrown framework into which the social context of bioethical debate has developed. Accordingly, his particular appeal to the notion of person-coupled with some subtle escamotages about human nonpersons-cannot justify a view which entails in the concrete the forsaking of any critique of the exclusive side of humanism. It seems that a discussion of the moral status of the countless nonhumans which are employed in biomedical practice, as well as in any other practice socially sanctioned by discrimination based on species, deserves from a book of ethics something more than a few dismissing lines out of nearly four hundred pages.

\section{Notes}

${ }^{1}$ See the discussion of this point in L. Wayne Sumner, "Subjectivity and Moral Standing," in L.W. Sumner, T. Attig, D. Callen (eds.), Values and Moral Standing (Bowling Green Studies in Applied Philosophy, VIII, 1986), p.1.

${ }^{2}$ Michael Tooley, "Abortion and Infanticide," Philosophy \& Public Affairs 2 (1), 1972, reprinted in Peter Singer (ed.), Applied Ethics (Oxford University Press, Oxford, 1986) pp. 57-85; see especially pp. 70-71. James Rachels, The End of Life. Euthanasia and Morality (Oxford University Press, Oxford, 1986), in particular p. 188. An partial list of the philosophers and bioethicists who have disputed the tenability of the sanctity of human life doctrine outside a religious framework would have to include: R.G. Frey, Rights, Killing and Suffering (Blackwell, Oxford, 1983); Jonathan Glover, Causing Deaths and Saving Lives (Penguin, Harmondsworth, 1977); John Harris, The Value of Life (Routledge and Kegan Paul, London, 1985); Helga Kuhse, The Sanctity-of-Life Doctrine in Medicine: A Critique (Clarendon Press, Oxford, 1987); and Peter Singer, Practical Ethics (Cambridge University Press, Cambridge, 1979, 1993²).

${ }^{3}$ Stephen Toulmin, "How Medicine Saved the Life of Ethics," in J. P. DeMarco and R. M. Fox (eds.), The Challenge of Applied Ethics (Routledge \& Kegan Paul, London, 1986), pp. 265-281

${ }^{4}$ Peter Singer, "Can bioethics be both rigorous and practical?," Réseaux, 53-54 (1987-1988), pp. 121-130. 
${ }^{5}$ This is a peculiar use of the phrase, since normally "moral community" refers to the whole body of moral patients, whatever their relative moral status, while, as we shall see, what Engelhardt is referring to is only a part of it. I shall however maintain the expression, and I shall resort to "moral domain" to indicate this larger group.

${ }^{6}$ In fact, I do not find the use of the term "transcendental" appropriate in this context, since Engelhardt is referring to a condition that, though in a limited sense a priori, is empirical.

${ }^{7}$ The mention recurs, though in a slightly different way, in Engelhardt's most recent book. See Hugo Tristram Engelhardt Jr., Bioethics and Secular Humanism (Trinity Press International, Philadelphia, 1991), p. 34. MacIntyre defends a version of virtue theory based on a neo-Aristotelian account of human good.

${ }^{8}$ Arthur Schopenhauer, On the Basis of Morality, trans. E.F.J. Payne (Library of Liberal Arts, 1965), II, 5.

${ }^{9}$ See Christina Hoff, The Moral Domain: An Inquiry into its Extent and Limits, Ph. D. dissertation, Brandeis University, 1979 (University Microfilms International, Ann Arbor, Michigan), p. 2.

${ }^{10}$ Inmanuel Kant, The Groundwork of the Metaphysic of Morals, trans. H. G. Paton (Harper \& Row, New York, 1964), p. 96.

${ }^{11}$ In fact-apart from God-Kant also takes into consideration the possible existence of immaterial beings: see, e.g., Immanuel Kant, "Duties to Animals and Spirits," in Lectures on Ethics, trans. Louis Infield (Harper \& Row, New York, 1963) pp. 239-241. But this is not relevant here.

${ }^{12}$ For this discussion I am clearly indebted to Edward Johnson, Species and Morality, Ph.D. dissertation, Princeton University, 1976 (University Microfilms International, Ann Arbor, Michigan), in particular pp. $143 \mathrm{ff}$.

${ }^{13}$ Though Engelhardt also mentions a form of explicit (actual) consent, related to the non-procedural interest in collectively administering common endeavors and resources, this aspect is of minor importance here.

${ }^{14}$ Peter Singer, Dernocracy and Disobedience (Clarendon Press, Oxford, 1973), p. 59.

${ }^{15}$ Engelhardt simply says "the innocent" (e. g., pp. 141, 144) but it is apparent from the whole context that what he means is innocent persons.

${ }^{16}$ On this issue, see in particular Evelyn Pluhar, "Moral Agents and Moral Patients," Between the Species 4 (1),1988, pp. 32-45 (especially p. 33 and p. 38-39).
${ }^{17}$ See the discussion in Steve F. Sapontzis, Morals, Reason, and Animals (Temple University Press, Philadelphia, 1987), pp. $145 \mathrm{ff}$.

${ }^{18}$ See again L. Wayne Sumner, "Subjectivity and Moral Standing," p.12. Sumner points out that the inference from a formal thesis about values to a substantive thesis about values is fallacious-as fallacious as the attempt to extract a substantive conclusion about the kinds of things which are colored from a formal premise about the conditions for anything's being colored.

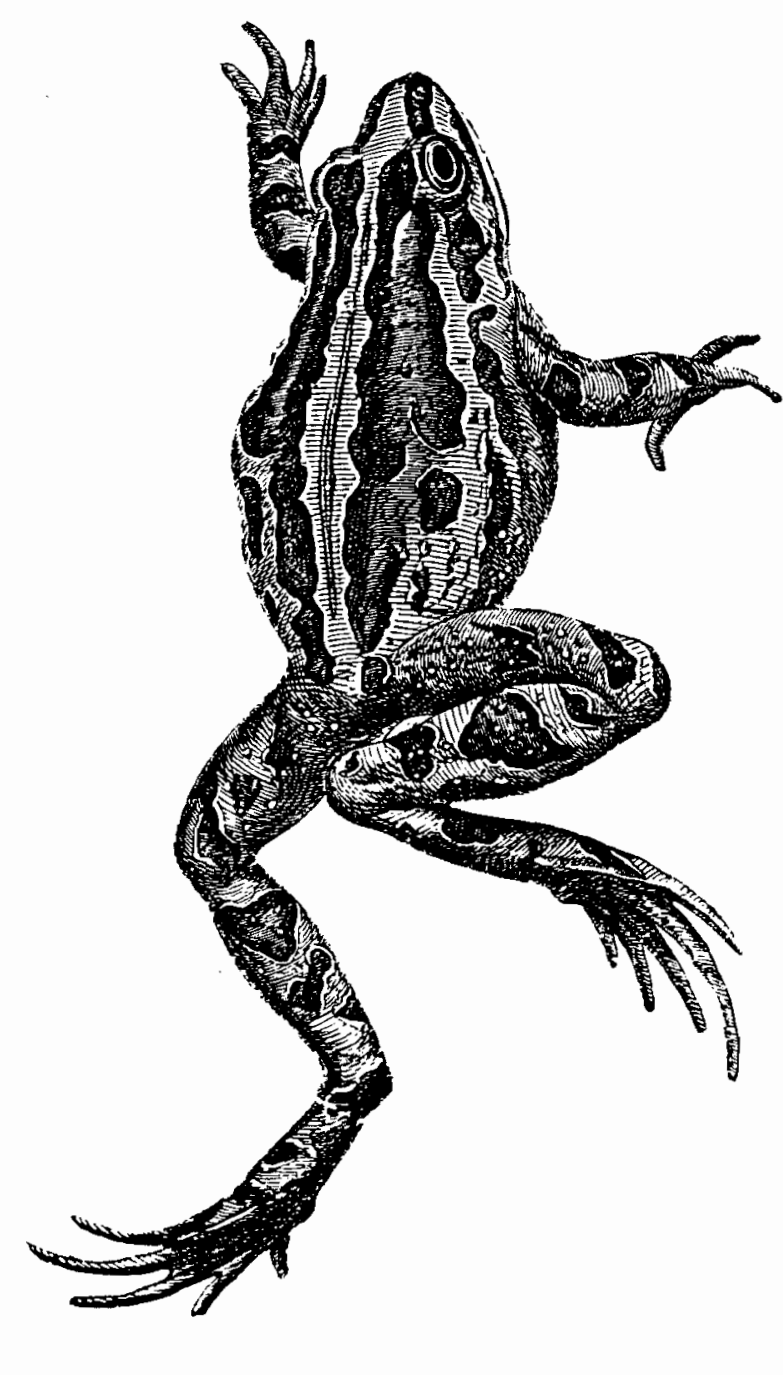

